ORIGINAL RESEARCH PAPER

\title{
CONSIDERING THE OXIDATIVE STABILITY OF COLD-PRESSED SESAME, SUNFLOWER, AND OLIVE OILS UNDER DIFFERENT STORAGE CONDITIONS
}

\author{
EHSAN SADEGHI ${ }^{1}$, AIDIN MAHTABANI $^{2}$, FARAHNAZ KARAMI $^{1 *}$ \\ Research Center for Environmental Determinants of Health (RCEDH), Kermanshah University of Medical \\ Sciences, Kermanshah, Iran \\ Department of Food Science and Technology, College of Agriculture, Kermanshah Branch, \\ Islamic Azad University, Kermanshah, Iran \\ *Corresponding author: farahnazk83@yahoo.com
}

Received on $26^{\text {th }}$ August 2019

Revised on $29^{\text {th }}$ October 2019

\begin{abstract}
This study evaluated the oxidative stability of olive, sesame, and sunflower oils at different temperatures $\left(4,25\right.$, and $\left.37^{\circ} \mathrm{C}\right)$ and in exposure to light for three months. Acidity, peroxide, anisidine, conjugated dienes (CD), and conjugated trienes (CT) and oil stability index (OSI) were measured to investigate the stability of the oils. For all samples, free fatty acid content was almost constant. Temperature and sunlight accelerated the oxidation specifically by an increase in peroxide value and CDs, but anisidine and CTs were not significantly influenced by these variables. The obtained results showed cold-pressed oils had a high tolerance against the formation of the oxidation secondary products. The OSIs were found to be $9.19,7.06$, and $4.73 \mathrm{~h}$ for sesame, sunflower, and olive oils, respectively. Among the tested oils, sesame oil had the highest stability. Generally, if storage conditions are optimized, cold-pressed oils can preserve their stability for a longer period.
\end{abstract}

Keywords: Storage stability, sesame, olive, sunflower, cold-pressed oils, vegetable oils

\section{Introduction}

Lifestyle has deep effects on human health. Today, since people have an increasing awareness of the harms of synthetic compounds, they tend to change their diet to prevent illnesses and consume natural products due to their health benefits. For this reason, the tendency for the consumption of cold-pressed edible oils has increased.

Cold-pressing is a process that does not use temperature or organic solvents for oil extraction, and purification of oil is done by settling, filtering or centrifuging

https://doi.org/10.35219/foodtechnology.2019.2.05 
(Celenk et al., 2018). Therefore, cold-pressed oils relative to refined ones are rich in sterols, carotenoids, phenolics, tocols, and other phytochemicals and are more valuable from a nutrition point of view (Kiralan et al., 2018).

Oxidative stability of edible oils is defined as their resistance to oxidation during storage and processing (Choe and Min, 2006).

Cold-pressed oils have higher antioxidant activity due to a higher content of natural antioxidants but have lower stability because of the higher extent of free fatty acids, chlorophylls, and peroxides (Kostadinovic-Velickovska and Mitrev, 2013).

The major factors involved in oxidative stability of edible oils include temperature, light, metals, and contact with oxygen. Oxidation products cause the loss of quality and nutritional value of vegetable oils. Moreover, they are toxic and danger the health of humans. Thus, it is essential to determine the stability of cold-pressed oils to predict the storage time with good characters.

Sesame oil is a valuable oil rich in essential fatty acids and bioactive compounds such as tocopherols, phytosterols, and lignans including sesamolin, sesamin, and sesaminol that are responsible for antioxidant activity and stability of this oil (Bopitiya and Madhujith, 2013).

Sunflower oil is a precious edible oil due to a light color, the low extent of saturated fatty acids, mild flavor, and resistance to high cooking temperatures, and substantial extractibility by pressing (Guinda et al., 2003).

Olive oil is one of the well-known vegetable oils owing to the desired taste and smell and high nutritional value. It is rich in monounsaturated fatty acids and phenolic components with a strong antioxidant activity that contributes to its stability and health benefits. Another minor compound in virgin olive oil is $\alpha$ tocopherol, which prevents the oxidation of oil at high temperatures (Gharby et al., 2016).

Generally, many factors affect the stability of cold-pressed oils and besides the composition of free fatty acids; natural antioxidants, storage conditions, quality of initial materials, and oil extraction circumstances can influence the resistance of oils. The stability of cold-pressed oils has been studied in different works. In this manner, the storage and oxidative stability of cold-pressed oils from cranberry, hemp, carrot, and caraway seeds (Parker et al., 2003), argan (Matthäus, 2013), rice bran (Ponchurdchai and Singkhonrat, 2016), almond, walnut and pistachio (Rabadán et al., 2018), flax seeds, grape seeds, and black cumin seeds (Kiralan et al., 2019), and rapeseed (Eftinzjijoska and Pavlovska, 2019) were investigated. However, there was low information about storage stability of sesame, sunflower, and olive cold-pressed oils in the literature. Thus, due to the importance of quality properties of the cold-pressed oils from consumers' viewpoint and increasing awareness of people about the storage conditions of these plant oils, this study investigated the stability of sesame, sunflower, and olive cold-pressed oils during storage under various temperatures (refrigerator, ambient, and $37^{\circ} \mathrm{C}$ ) and in exposure to light. Quality parameters to assay the stability of the oils, including 
free fatty acid content, peroxide value, $\mathrm{p}$-anisidine value, conjugated dienes and trienes and oil stability index (OSI) were measured.

\section{Materials and methods}

\section{Materials}

Fresh oils of olive, sesame, and sunflower were collected from three different regions (Golestan, Elaheyeh, and 22 Bahman) in Kermanshah province, Iran. Chemical materials with analytical grade were purchased from Merck (Darmstadt, Germany)

\section{Sample preparation}

The collected cold-pressed oils in $250 \mathrm{~mL}$ volume were stored in glass transparent bottles at 4 and $25^{\circ} \mathrm{C}$ temperatures in dark and in exposure to light as well as $37^{\circ} \mathrm{C}$ to investigate the effects of temperature and light on oil stability. A sampling of oils was done every fifteen days for three months. All tests were performed in triplicate.

\section{Chemical parameters}

Chemical parameters, including free fatty acid content (FFA) (cd 3a-63), Panisidine value (P-AnV) (cd 18-90), and peroxide value (PV) (cd 8-53) were measured according to the official methods of AOCS (1990).

\section{Free fatty acids analysis}

The FFAs content was determined by adding the neutralized solvent (a mixture of isopropyl alcohol and toluene) $(125 \mathrm{~mL})$ to the oil sample $(20 \mathrm{~g})$ and titration with standard alkali in the presence of phenolphthalein as indicator $(2 \mathrm{~mL})$ to the first permanent pink color. The acid value ( $\mathrm{mg} \mathrm{KOH} / \mathrm{g}$ of oil) was count by the following equation:

$$
\text { Acid value }=\frac{(A-B) \times N \times 56.1}{W}
$$

where $\mathrm{A}$ and $\mathrm{B}$ are $\mathrm{mL}$ of standard alkali for titration of the sample and blank (the solvent mixture), respectively. The $\mathrm{N}$ is the normality of standard alkali and $\mathrm{W}$ is the weight of the sample (g). FFAs content (\% oleic acid) was calculated by dividing the acid value by 1.99 .

\section{Peroxide value}

For PV, the method of acetic acid-chloroform $(3: 2)$ was used. The solvent $(30 \mathrm{~mL})$ was added to the oil $(5 \mathrm{~g})$. Then, $0.5 \mathrm{~mL}$ of saturated $\mathrm{KI}$ was added and the sample was shaken for $1 \mathrm{~min}$. After that, $30 \mathrm{~mL}$ of distilled water was added and the liberated $\mathrm{I}_{2}$ was titrated by sodium thiosulfate $(0.1 \mathrm{~N})$. The starch was used as an indicator. The PV (meq peroxide $/ \mathrm{kg}$ oil) was determined as follow:

$$
\text { Peroxide value }=\frac{(S-B) \times N \times 1000}{W}
$$


where S - volume of titrant, B - $\mathrm{ml}$ of titrant for blank (without oil), $\mathrm{N}$ - normality of sodium thiosulfate solution, and $\mathrm{W}$ - weight of the sample.

\section{$P$-anisidine value}

For measuring the anisidine value, the oil sample $(0.5 \mathrm{~g})$ was poured in a $25 \mathrm{~mL}$ volumetric flask, solved in isooctane and diluted to volume by this solvent. The absorbance of the sample was read at $350 \mathrm{~nm}$ with the solvent as blank. Then, 5 $\mathrm{mL}$ of the oil solution and $5 \mathrm{~mL}$ of the solvent were poured in two test tubes separately, $1 \mathrm{~mL}$ of anisidine reagent $(0.25 \mathrm{~g} / 100 \mathrm{ml}$ of glacial acetic acid) was added to each test tube and after $10 \mathrm{~min}$, the absorbance of the oil solution (the first test tube) was read at $350 \mathrm{~nm}$ with the solvent as blank (the second test tube). The anisidine value was calculated as follow:

$$
P-A n V=\frac{25 \times(1.2 A s-A b)}{m}
$$

where As - the absorbance of the oil solution after reaction with anisidine reagent, $\mathrm{Ab}$ - absorbance of the oil solution, and $\mathrm{m}$ - weight of oil (g).

\section{Conjugated dienes and trienes determination}

Conjugated dienes and trienes were determined as the extinction coefficient at 232 $\mathrm{nm}$ and $268 \mathrm{~nm}$ (IUPAC, 1987) by a spectrophotometer. For this mean, the oil samples (0.01-0.03 g) are dissolved in isooctane and diluted with that to volume in a $25 \mathrm{~mL}$ volumetric flask.

\section{Oil stability index (OSI)}

A Metrohm Rancimat (model 679) was used to measure the oxidative stability index of cold-pressed oils at $110^{\circ} \mathrm{C}$ and airflow of $20 \mathrm{~L} / \mathrm{h}$ according to ISO-6886 (2006).

\section{Statistical analysis}

Statistical analysis was performed based on a factorial design in triplicate. Data analysis was performed by one-way ANOVA, and Duncan test was applied to detect significant differences $(\mathrm{p}<0.05)$.

\section{Results and discussion}

\section{Free fatty acid content (FFA)}

Free fatty acids are the main products of oil hydrolysis. Also, they are produced from aldehydes during oxidation. The extent of $\mathrm{FFA}_{\mathrm{s}}$ of olive oil was in the range of 2.8-3.3, 2.8-3.45, and 2.8-3.71 at 4,25 , and $37^{\circ} \mathrm{C}$ for 90 days storage, respectively (Figure 1a). For all temperatures after day 15, the content of $\mathrm{FFA}_{\mathrm{s}}$ was increased but it was almost constant until day 90. Similar results were observed in the work of Ying et al. (2018) by storing some unconventional cold-pressed oils for 6 and 12 days at $60{ }^{\circ} \mathrm{C}$. The acidity of olive oil at $37^{\circ} \mathrm{C}$ was slightly higher relative to 4 and $25^{\circ} \mathrm{C}$. However, the difference between temperatures was not significant (Table 1). Zeb et al. (2008) examined the effect of UV, temperature, sun, and white light on olive oil stability for 14 days. They observed the highest acidity in the 
oven $\left(72^{\circ} \mathrm{C}\right)$ and white light samples. Acidity was in the ranges of $0.23-0.4,0.23$ 0.4 , and $0.23-0.46$ for sesame oil and 0.18-0.3, 0.18-0.3, and 0.18-0.4 for sunflower oil at the mentioned temperatures. These amounts were lower than those of fresh cold-pressed sesame oils from Morocco (0.92), Sudan (0.49), Congo (1.8), and Nigeria (0.9) (Gharby et al., 2017) as well as fresh cold-pressed sunflower (0.72) and pumpkin oil (0.68) (Poiana et al., 2009) but were higher than Macadamia oil, Avocado oil, Sesame oil, and Safflower oil after 12 months storage at $20^{\circ} \mathrm{C}$ in 12/12h dark/light (Prescha et al., 2014). Acidity results in sesame and sunflower oils were similar to those of olive oil. According to the obtained data, sunflower oil had the lowest $\mathrm{FFA}_{\mathrm{s}}$ content, followed by sesame and olive oil, respectively, and there were significant differences between treatments (Table 1). Also, acidity in samples being exposed to light was the same as that of samples in darkness (Figure 1b). Totally, FFAs content in sesame and sunflower oils was lower than Codex Alimentarius standards (Acid value: $4.0 \mathrm{mg} \mathrm{KOH} / \mathrm{g}$ Oil) but was higher in olive oil (Codex Alimentarius, 2001). The higher acidity in olive oils is representative of enzymatic hydrolysis during harvesting, displacing and oil extraction (Gharby et al., 2015).
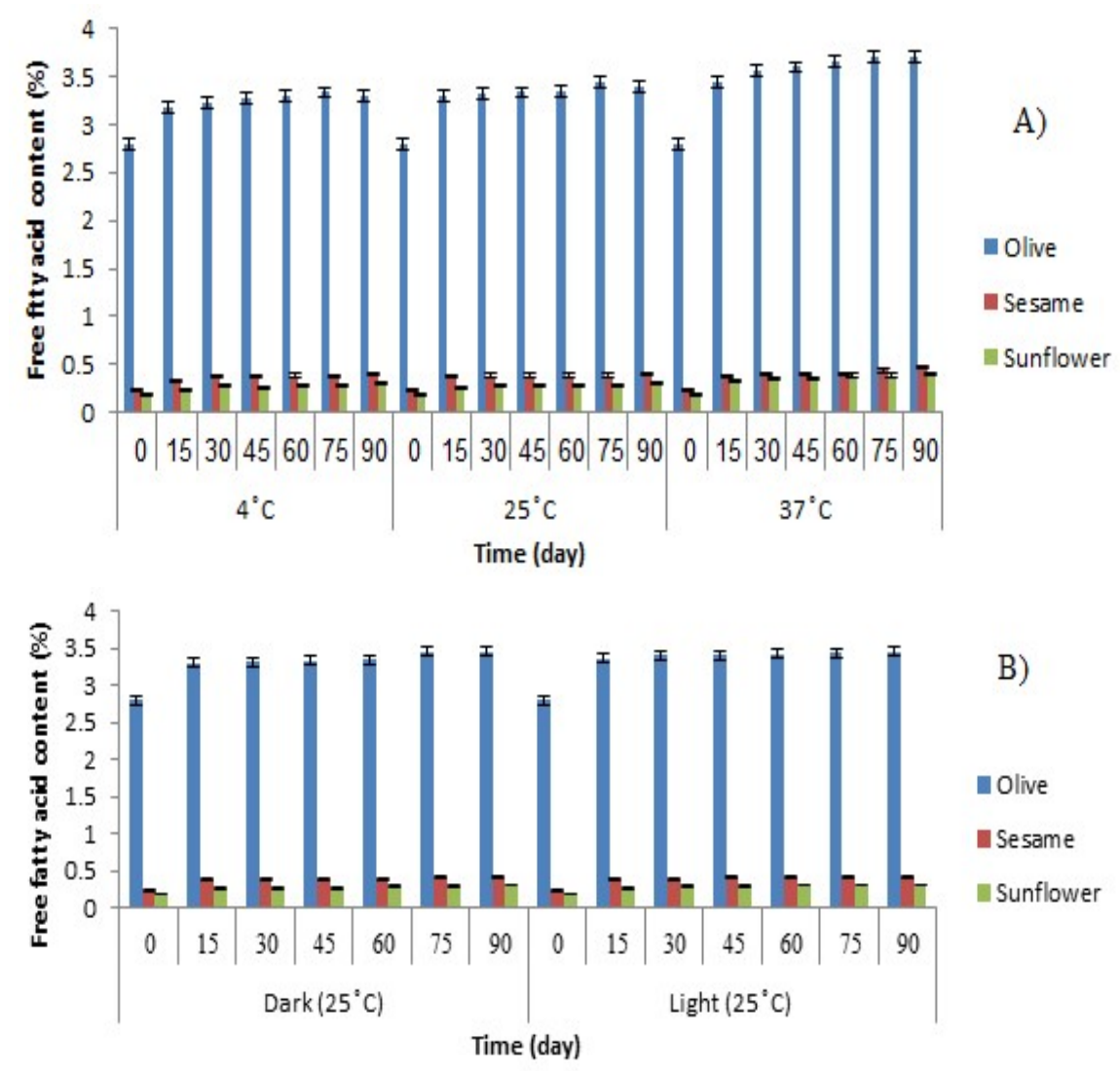

Figure 1. (a) Effect of temperature on free fatty acid content of cold-pressed oils during the storage period, (b) Effect of light on free fatty acid content of cold-pressed oils during the storage period 
Table 1. Mean of squares for chemical traits of sesame, olive and sunflower oils at temperatures 4,25 and $37^{\circ} \mathrm{C}$

\begin{tabular}{|c|c|c|c|c|c|c|}
\hline \multirow[t]{2}{*}{$\begin{array}{ll}\text { Source } & \text { of } \\
\text { variation } & \\
\end{array}$} & \multirow[t]{2}{*}{ DF } & \multicolumn{5}{|c|}{ Mean of squares } \\
\hline & & Acidity & PV & P-AnV & CD & CT \\
\hline Oils & 2 & $188.5452545^{*}$ & $1981.577619 *$ & $606.002153^{*}$ & $199.057858 *$ & $16.10954339 *$ \\
\hline $\begin{array}{l}\text { Storage } \\
\text { period }\end{array}$ & 6 & $0.3544005^{\mathrm{ns}}$ & $331.106032 *$ & $1.058412^{\mathrm{ns}}$ & $351.877837 *$ & $10.15314131 *$ \\
\hline Temperature & 2 & $0.3471370^{\mathrm{ns}}$ & $496.241111^{*}$ & $0.630750^{\mathrm{ns}}$ & $909.148102 *$ & $0.03273981^{\mathrm{ns}}$ \\
\hline $\begin{array}{l}\text { Oils * } \\
\text { Storage } \\
\text { period }\end{array}$ & 12 & $0.0981360^{\mathrm{ns}}$ & $89.255767 *$ & $1.265829^{\mathrm{ns}}$ & $11.869689^{\mathrm{ns}}$ & $0.50321777^{\mathrm{ns}}$ \\
\hline $\begin{array}{l}\text { Oils * } \\
\text { Temperature }\end{array}$ & 4 & $0.1155791^{\mathrm{ns}}$ & $735.732540^{*}$ & $0.109891^{\mathrm{ns}}$ & $16.911540^{\mathrm{ns}}$ & $0.49582593^{\mathrm{ns}}$ \\
\hline $\begin{array}{l}\text { Temperature } \\
* \text { Storage } \\
\text { period }\end{array}$ & 12 & $0.0127833^{\mathrm{ns}}$ & $36.030741^{\mathrm{ns}}$ & $0.552576^{\mathrm{ns}}$ & $40.205194 *$ & $1.38384475^{\mathrm{ns}}$ \\
\hline $\begin{array}{l}\text { Oils * } \\
\text { Storage } \\
\text { period * } \\
\text { Temperature }\end{array}$ & 24 & $0.0043347^{\mathrm{ns}}$ & $52.563095^{*}$ & $0.268289^{\mathrm{ns}}$ & $8.498934^{\mathrm{ns}}$ & $0.35340077^{\mathrm{ns}}$ \\
\hline Error & 126 & 3.5210767 & 28.47878 & 2.312303 & 10.181259 & 1.1064930 \\
\hline
\end{tabular}

$*=$ significant at $\alpha=5 \%$, ns $=$ not significant

\section{Peroxide value (PV)}

The PV measurement is a good indicator for the evaluation of oil quality in primary oxidation stages. Increasing in PV is observed only when its formation rate is higher than its breakdown rate. Peroxide value was in the ranges of 12.13-20.93, 2.06-7.26, 4-9.93 for olive, sesame, and sunflower at $4{ }^{\circ} \mathrm{C}, 12.13-17.4,2.06-6.53$, 418.4 at $25^{\circ} \mathrm{C}$ in darkness, and $12.13-15.53,2.06-9.8$, and $4-42.06$ at $37^{\circ} \mathrm{C}$ for the mentioned oils, respectively (Figure 2a). The results of PV for stored oils at room temperature in darkness were higher than those of sesame oil stored under 12/12 light/dark condition for 12 months (Prescha et al., 2014), similar to sunflower oil stored for 120 days (Poiana et al., 2009) and olive oil stored for 21 months at room temperature (Gomez-Alonso et al., 2007).

For olive oil, this index was higher at $4{ }^{\circ} \mathrm{C}$ and $25^{\circ} \mathrm{C}$ than $37^{\circ} \mathrm{C}$. This is perhaps due to this fact that the destruction rate of peroxides is more than their formation rate when the temperature increases because heating makes peroxides unstable. In sesame, PV was almost in the same range at all temperatures but slightly increased after day 60 of storage at $37^{\circ} \mathrm{C}$. The extent of peroxides in sunflower oil was increased with temperature, and this enhancement was significantly higher at $37^{\circ} \mathrm{C}$ (Table 1). Various factors influence oil oxidation, including fatty acid composition of the oil, free fatty acids, light, temperature, type, and dose of oxygen, transition metals, peroxides, mono and diacylglycerols, pigments, thermally oxidized compounds, oil processing, and antioxidants (Choe and Min, 2006). Greater 
increase in the PV of sunflower oil relative to sesame and olive oil at $37^{\circ} \mathrm{C}$ is attributed to higher polyunsaturated fatty acids (linoleic acid) in sunflower oil, which makes it prone to oxidation. Marmesat et al. (2009) reported more peroxide value in conventional sunflower oil (high linoleic) than high-oleic sunflower oil. In a comparison of the cold-pressed oils in darkness and in exposure to daylight, PV was purposefully enhanced in all oils exposed to light relative to samples in the darkness; 12.13-51.4, 2.06-33.13, 4-37.26 for olive, sesame and sunflower oils, respectively (Table 2 and Figure $2 b$ ). These results were in agreement with the findings reported by Popa et al. (2017). Also, olive oil had greater PV among oils in exposure to light. This difference is related to the green color of olive that is attributed to chlorophyll pigment. It acts as a photosensitizer and produces singlet oxygen by absorbing light energy and transforming it into triplet oxygen. Then, the formation of peroxides is accelerated. Similar results were observed by Jung et al. (2015). They declared higher PV in soybean oil stored under light rather than soybean oil stored under thermal oxidation. Among the oils, sesame oil had the lower peroxide than the established limit by Codex Alimentarius (2001) (15 $\mathrm{meq} / \mathrm{kg}$ for cold-pressed oils) at all temperatures, which indicates it has good oxidative stability because of natural antioxidants, including sesamol, sesamolin, sesamin, and tocopherols (mostly $\gamma$-tocopherol) (Gharby et al., 2017).

Table 2. Mean of squares for chemical traits of sesame, olive and sunflower oils at $25^{\circ} \mathrm{C}$ in dark and in exposure to light

\begin{tabular}{|c|c|c|c|c|c|c|}
\hline \multirow{2}{*}{$\begin{array}{l}\text { Source of } \\
\text { variation }\end{array}$} & \multirow[t]{2}{*}{ DF } & \multicolumn{5}{|c|}{ Mean of squares } \\
\hline & & Acidity & PV & P-AnV & $\mathrm{CD}$ & $\mathrm{CT}$ \\
\hline Oils & 2 & $124.0648437 *$ & $1551.61166 *$ & $356.805773 *$ & $107.932498 *$ & $6.44906270 *$ \\
\hline $\begin{array}{l}\text { Storage } \\
\text { period }\end{array}$ & 6 & $0.1996601^{\mathrm{ns}}$ & $1049.13589 *$ & $0.5055749^{\mathrm{ns}}$ & $383.780171 *$ & $5.73991290 *$ \\
\hline $\begin{array}{l}\text { Dark and } \\
\text { light }\end{array}$ & 1 & $0.0298698^{\mathrm{ns}}$ & $7786.43055 *$ & $0.1976198^{\mathrm{ns}}$ & $101.682350 *$ & $0.08228889^{\mathrm{ns}}$ \\
\hline $\begin{array}{l}\text { Oils * } \\
\text { Storage } \\
\text { period }\end{array}$ & 12 & $0.0575501^{\mathrm{ns}}$ & $34.280185^{\mathrm{ns}}$ & $0.5569312^{\mathrm{ns}}$ & $7.681633^{\mathrm{ns}}$ & $0.20601617^{\mathrm{ns}}$ \\
\hline $\begin{array}{l}\text { Oils * } \\
\text { Dark and } \\
\text { light }\end{array}$ & 2 & $0.0104103^{\mathrm{ns}}$ & 204.916746 * & $1.9347817^{\mathrm{ns}}$ & $4.769743^{\mathrm{ns}}$ & $0.22685794^{\mathrm{ns}}$ \\
\hline $\begin{array}{l}\text { Dark and } \\
\text { light } * \\
\text { Storage } \\
\text { period }\end{array}$ & 6 & $0.0015569^{\mathrm{ns}}$ & $454.174630 *$ & $0.8357310^{\mathrm{ns}}$ & $42.865980 *$ & $1.32156898^{\mathrm{ns}}$ \\
\hline $\begin{array}{l}\text { Oils * } \\
\text { Storage } \\
\text { period * } \\
\text { Dark and } \\
\text { light }\end{array}$ & 12 & $0.0004168^{\mathrm{ns}}$ & $32.081931^{\mathrm{ns}}$ & $0.3363095^{\mathrm{ns}}$ & $3.189525^{\mathrm{ns}}$ & $0.11437067^{\mathrm{ns}}$ \\
\hline Error & 84 & 3.6624817 & 48.88040 & 2.0828770 & 14.115428 & 0.9251345 \\
\hline
\end{tabular}

$*=$ significant at $\alpha=5 \%$, ns $=$ not significant 

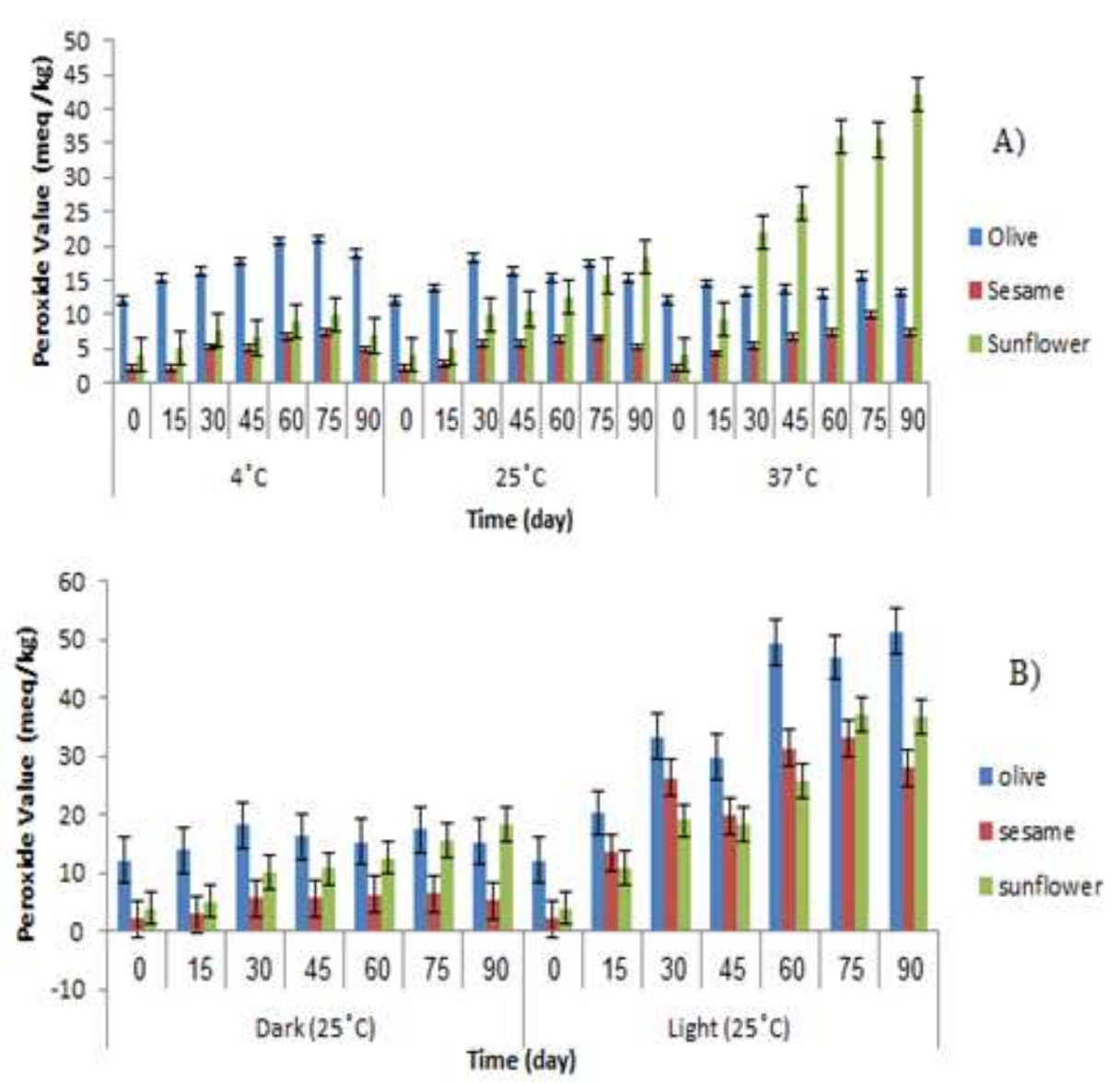

Figure 2. (a) Effect of temperature on peroxide value of cold-pressed oils during the storage period, (b) Effect of light on peroxide value of cold-pressed oils during the storage period

\section{P-anisidine value (P-An V)}

Anisidine value is an indicator of secondary oxidation products and measures nonvolatile aldehydes. The P-AnVs had small changes for all oils at all three temperatures and all storage periods and were in the ranges of 6-7.3, 0.26-0.8, and 2.35-3.4 at $4{ }^{\circ} \mathrm{C}$ for olive, sesame, and sunflower oils, respectively (Table 1). These values were 6-7.45, 0.26-1.45, and 2.5-3.4 at $25^{\circ} \mathrm{C}$ and 5.41-7.7, 0.26-0.96, and 2.53.4 at $37^{\circ} \mathrm{C}$ for the stated oils (Figure 3a). Similar results were obtained by Prescha et al. (2014) for sesame oil regarding the oxidative stability of cold-pressed oils, but lower values were obtained by them (0.2-0.3) during 12 months of storage. Also, no significant difference was observed between the anisidine of samples in darkness and those exposed to sunlight. The AnVs for olive, sesame, and sunflower oils under light were 5.55-7.1, 0.26-1.3, and 2.7-3.4, respectively (Figure 3b). There is very limited information about the AnV of cold-pressed oils. In general, the results showed the very low formation of secondary oxidation products in 
natural oils enriched in indigenes antioxidants. However, sesame oil had the lowest anisidine value among the cold-pressed oils, and their difference in this parameter was significant for storage under various conditions.
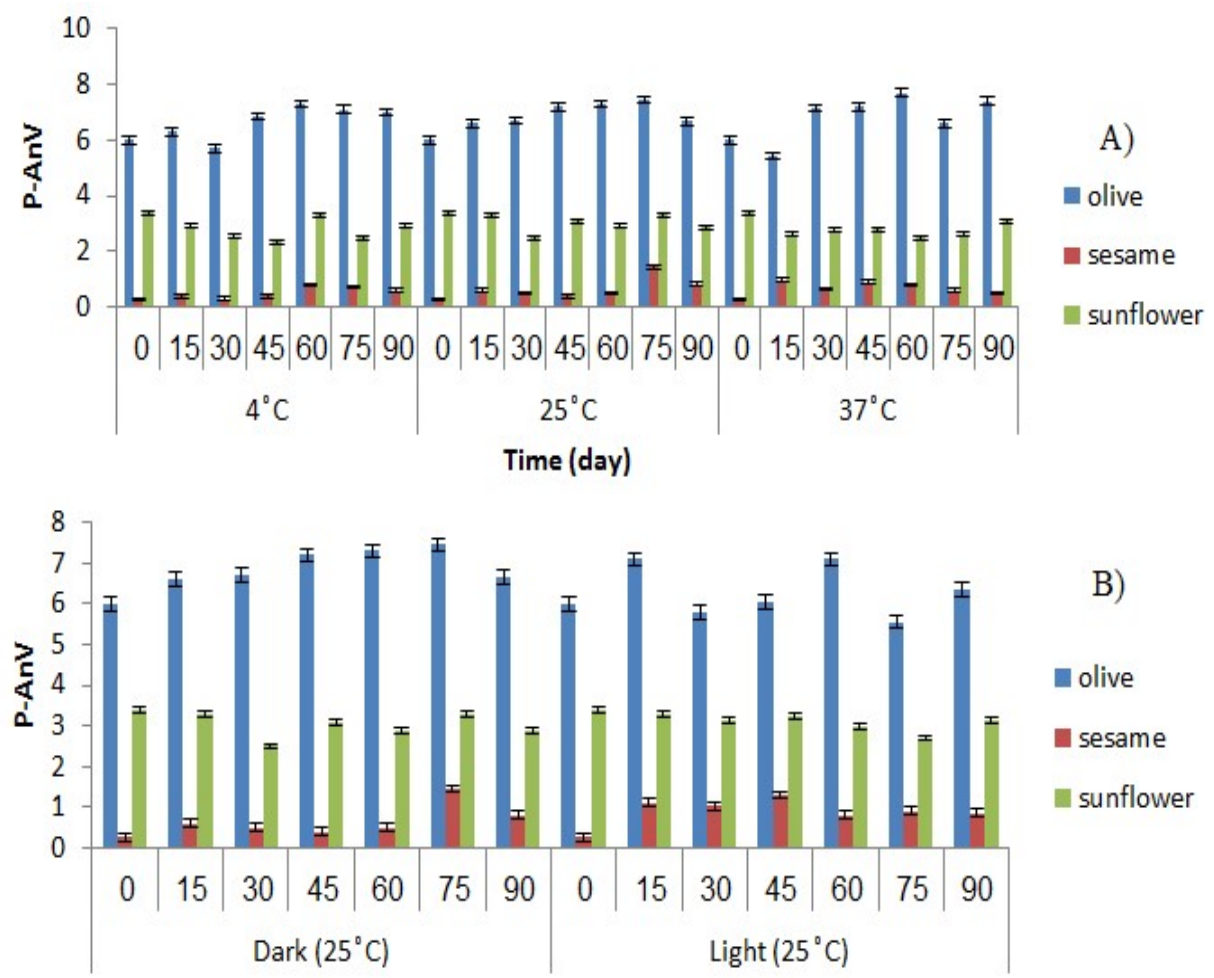

Figure 3. (a) Effect of temperature on the anisidine value of cold-pressed oils during the storage period, (b) Effect of light on the anisidine value of cold-pressed oils during the storage period

\section{Conjugated dienes (CD) and conjugated trienes (CT)}

Instantly after the formation of peroxides as primary oxidation products, rearrangement of non-conjugated double bonds in unsaturated lipids occurs, and conjugated compounds are formed, which absorb UV at $232 \mathrm{~nm}$. The existence of polyunsaturated fatty acids containing three or more double bonds in lipids and their further adornment during oxidation resulted in the production of conjugated trienes, which absorb at 268nm (Poiana et al., 2012). The contents of CDs and CTs during 90 days storage are shown in Figures 4 and 5. According to Figure 4a, the amounts of CDs in olive, sesame, and sunflower oils were in the ranges of 3.77$9.13,1.88-6.23$, and $3.85-12.58$ at $4{ }^{\circ} \mathrm{C}, 3.77-17.83,1.88-14.4$, and $3.85-18$ at $25^{\circ} \mathrm{C}$ in darkness, and 3.77-17.91, $1.88-15.75$, and $3.85-25.83$ at $37^{\circ} \mathrm{C}$, respectively. In line with the obtained data, the formation of conjugated dienes significantly increased with a rise in temperature and storage period (Table 1). Similar results were observed by Gharby et al. (2016); Gomez-Alonso et al. (2007); Kiralan and Ramadan (2016); Lerma-Garcia et al. (2009); and Hrncirik and Fritsche (2005). 
The higher CDs in sunflower oil were due to its greater unsaturation (linoleic acid). The values of CDs in the samples exposed to sunlight were greater but not for all time periods.

The amounts of CTs for olive, sesame, and sunflower oils were $0.47-3.16,0-1.625$, and $0.8-3.45$ at $4{ }^{\circ} \mathrm{C}, 0.47-2.41,0-2.41$, and $0.8-2.85$ at $25^{\circ} \mathrm{C}$ in darkness, and $0.47-$ $2.89,0-1.95$, and $0.8-3.08$ at $37^{\circ} \mathrm{C}$, respectively. The content of conjugated trienes enhanced during storage at all temperatures although this increase was not regular; however, the significant difference was not observed in various temperatures. Also, a significant difference was not found between samples in darkness and those exposed to light (Table 2). Unfortunately, there is very limited information about the changes in CDs and CTs in cold-pressed oils under diverse storage conditions. However, increment in oxidation parameters, including CTs as a function of storage time has been reported by several researchers (Gomez-Alonso et al., 2007; Lerma-Garcia et al., 2009; Seleim et al., 2008). In agreement with other parameters, sesame oil was the best oil.
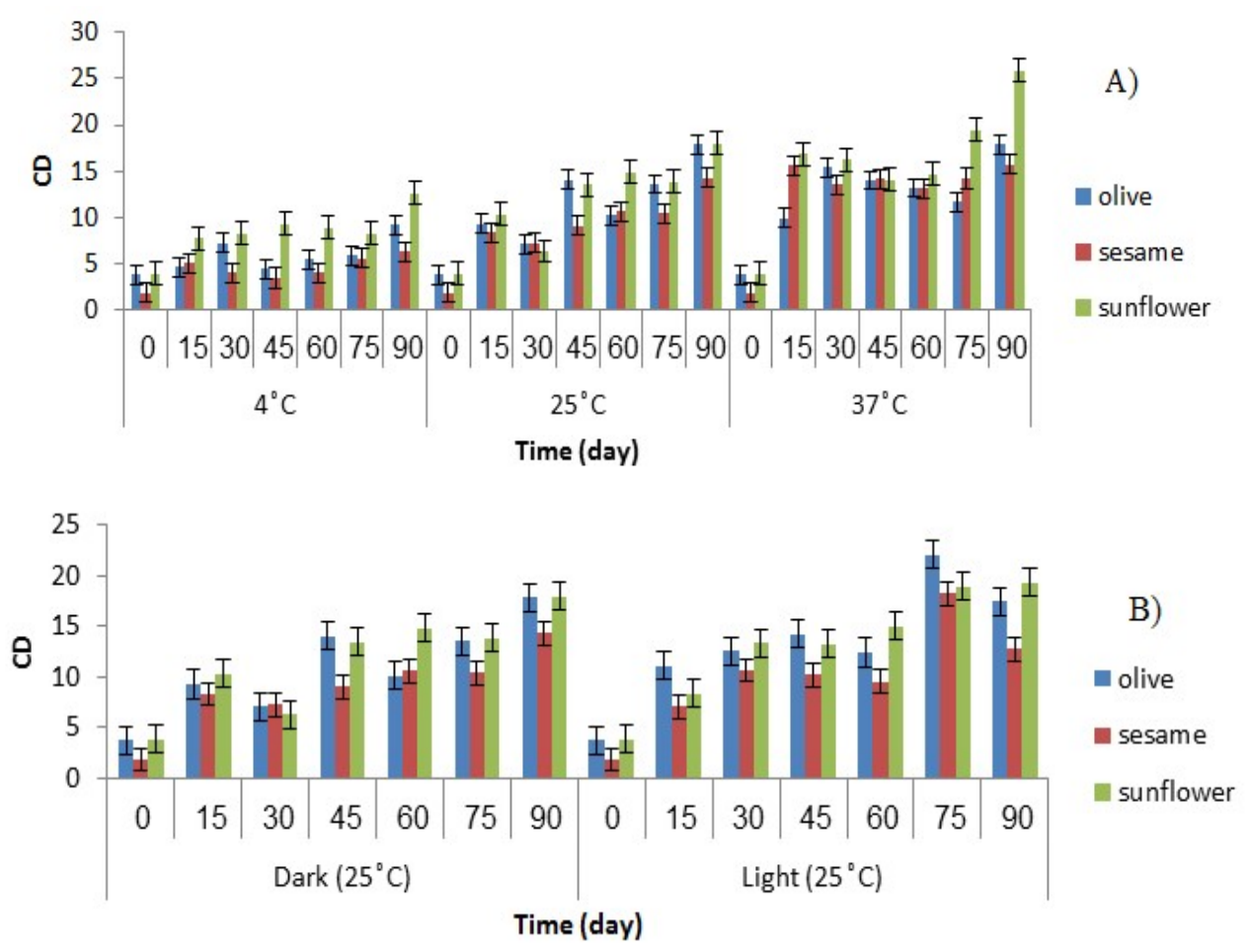

Figure 4. (a) Effect of temperature on Conjugated dienes of cold-pressed oils during the storage period, (b) Effect of light on Conjugated dienes of cold-pressed oils during the storage period 


\section{Oil stability index (OSI)}

The needed time for the extension of measurable rancidity in fats and oils is determined by the oil stability index, which was measured by the Rancimat system. The average and standard deviation of OSIs for olive, sesame, and sunflower oils were $7.06 \pm 0.14,9.19 \pm 0.42$, and $4.73 \pm 0.43 \mathrm{~h}$, respectively. The gained values in our study were lower than sunflower oil $(7.4 \mathrm{~h})$, high-oleic sunflower oil/sunflower oil $(10.1 \mathrm{~h})$, high oleic sunflower oil $(20.1 \mathrm{~h})$, and olive oil $(45 \mathrm{~h})$ at $100^{\circ} \mathrm{C}$ (Marquez-Ruiz et al., 2008), olives (Leccino and Frantoio cvs) (18.83 and $16.61 \mathrm{~h}$ ) at $110^{\circ} \mathrm{C}$ (Najafi et al., 2015), and sesame $(28.5 \mathrm{~h})$ and olive $(27 \mathrm{~h})$ oils at $110^{\circ} \mathrm{C}$ (Gharby et al., 2017), but were higher than sunflower $(2.6 \mathrm{~h})$ and sesame $(4.2 \mathrm{~h})$ oils at $120^{\circ} \mathrm{C}$ (Velickovska et al., 2015).
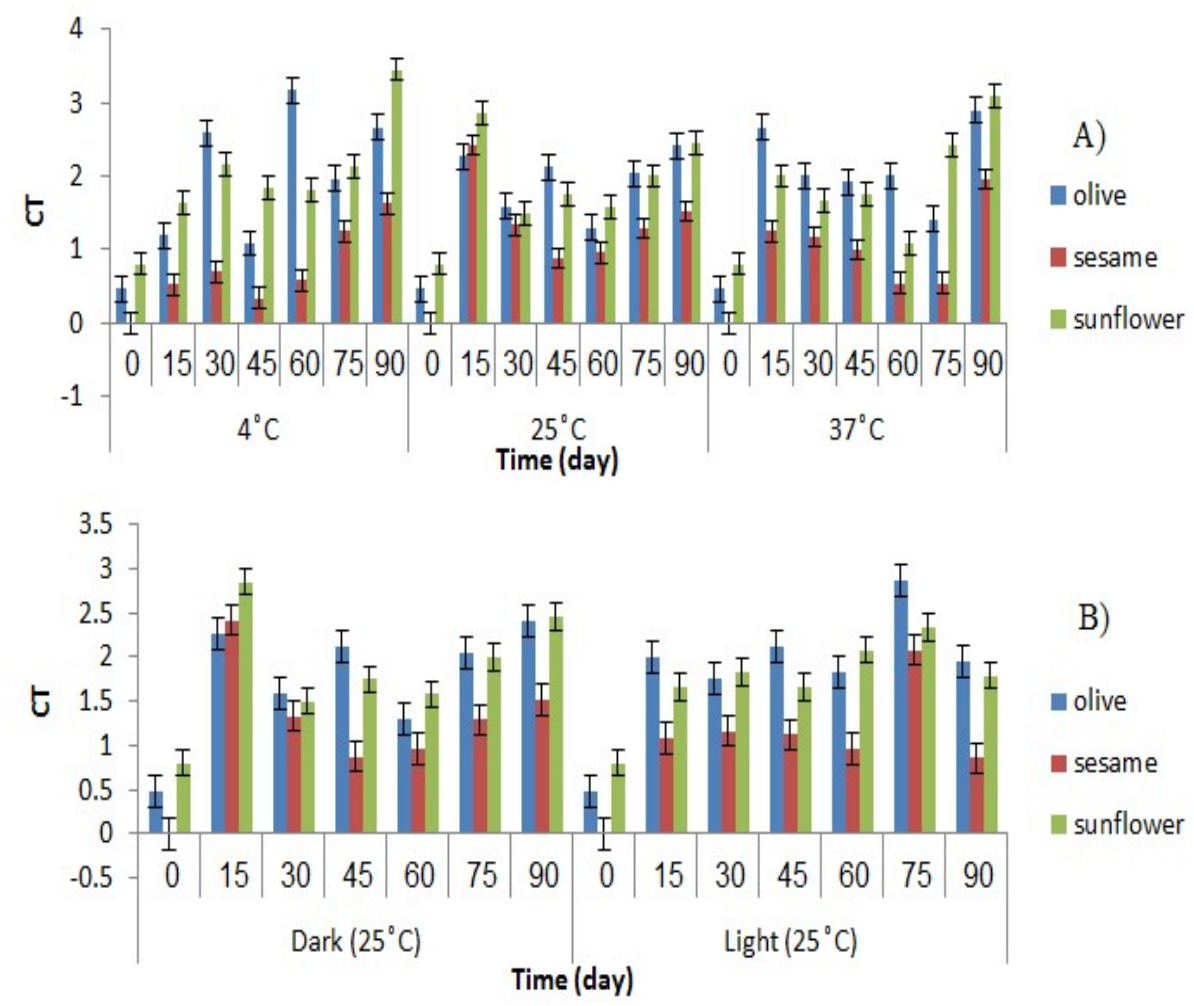

Figure 5. (a) Effect of temperature on Conjugated trienes of cold-pressed oils during the storage period, (b) Effect of light on Conjugated trienes of cold-pressed oils during the storage period

The profile of fatty acids and natural antioxidant compounds in cold-pressed oils resulted in diversity in oxidative stability (Aparicio et al., 1999). Also, the quality of primary materials and oil extraction conditions affect its resistance. The lower OSI in sunflower oils can be related to the higher ratio of linoleic/oleic acid in these oils. 


\section{Conclusions}

The results of various parameters showed that increment in temperature caused oxidation acceleration in cold-pressed oils. Also, exposure to the sunlight markedly increased the deterioration of oils, especially olive oil. Therefore, it is recommended these oils to be stored in the refrigerator or at room temperature in darkness and be kept away from exposure to light. Among the tested oils, sesame had the highest oxidative stability. Probably, we can say that oil storage conditions are optimized, these natural oils preserve their stability at least for three months, but more studies are needed to provide an accurate estimation.

\section{Acknowledgments}

We thank for the supports of Kermanshah University of Medical Sciences for proceeding of a research project with grant number 96487 .

\section{References}

AOCS. 1990. Official methods and recommended practices of the American oil chemists' society, AOCS Press, Champaign IL.

Aparicio, R., Roda, L., Albi, M.A., Gutierrez, F. 1999. Effect of various compounds on virgin olive oil stability measured by Rancimat. Journal of Agricultural and Food Chemistry, 47, 4150-4155.

Bopitiya, D., Madhujith, T. 2013. Antioxidant activity and total phenolic content of sesame (Sesamum indicum L.) seed oil. Tropical Agricultural Research, 24(3), 296 - 302.

Celenk, V., Gumus, Z., Auston Argon, Z., Buyukhelvacigil, M., Karasulu, E. 2018. Analysis of Chemical Compositions of 15 Different Cold-Pressed Oils Produced in Turkey: A Case Study of Tocopherol and Fatty Acid Analysis. Journal of the Turkish Chemical Society, Section A: Chemistry, 5(1), 1-18.

Choe, E., Min D.B. 2006. Mechanisms and factors for edible oil oxidation. Comprehensive Reviews in Food Science and Food Safety, 5, 169-186.

Codex Alimentarius. 2001. Fats, Oils and Related Products, (2nd ed.). FAO/WHO Food Standards Programme, Rome, Italy.

Eftinzjijoska, H., Pavlovska, G. 2019. Stability of oil from seed rape with garlic under various conditions. Journal of Agricultural and Plant Sciences, 17(1), 51-56.

Gharby, S., Harhar, H., Bouzoubaa, Z., Asdadi, A., El Yadini, A., Charrouf, Z. 2017. Chemical characterization and oxidative stability of seeds and oil of sesame grown in Morocco. Journal of the Saudi Society of Agricultural Sciences, 16(2), 105-111.

Gharby, S., Harhar, H., Guillaume, D., Roudani, A., Boulbaroud, S., Ibrahimi, M., Ahmad, M., Sultana, S., Ben Hadda, T., Chafchaouni-Moussaoui, I., Charrouf, Z. 2015. Chemical investigation of Nigella sativa L. seed oil produced in Morocco. Journal of the Saudi Society of Agricultural Sciences, 14(2), 172-177.

Gharby, S., Harhar, H., Matthäus, B., Bouzoubaa, Z., Charrouf, Z. 2016. The chemical parameters and oxidative resistance to heat treatment of refined and extra virgin Moroccan Picholine olive oil. Journal of Taibah University for Science, 10, 100-106. 
Gomez-Alonso, S., Mancebo-Campos, V., Desamparados Salvador, M., Fregapane, G. 2007. Evolution of major and minor components and oxidation indices of virgin olive oil during 21 months storage at room temperature. Food Chemistry, 100, 36-42.

Guinda, Á., Dobarganes, M.C., Ruiz-Mendez, M.V., Mancha, M. 2003. Chemical and physical properties of a sunflower oil with high levels of oleic and palmitic acids. European Journal of Lipid Science and Technology, 105(3-4), 130-137.

Hrncirik, K., Fritsche, S. 2005. Relation between the endogenous antioxidant system and the quality of extra virgin olive oil under accelerated storage conditions. Journal of Agricultural and Food Chemistry, 53, 2103-2110.

International Union of Pure and Applied Chemistry (IUPAC). 1987. Standard Methods for the Analysis of Oils, Fats and Derivatives, Blackwell Scientific, London.

ISO-6886 (ISO Official Method 6886). 2006. Determination of Oxidative Stability (Accelerated Oxidation Test), International Standard Organization (ISO), Geneva, Switzerland.

Jung, M.Y., Choi, D.S., Oh, C.H., Yoon, S.H. 2015. Autoxidation and photooxidation of triacylglycerols containing conjugated linoleic acids. Food Science and Biotechnology, 24, 1987-1994.

Kiralan, M., Alik, G., Kiralan, S., Ramadan, M.F. 2018. Monitoring stability and volatile oxidation compounds of cold-pressed flax seed, grape seed and black cumin seed oils upon photo-oxidation. Journal of Food Measurement and Characterization, 12, 616621.

Kiralan, M., Çalikb, G., Kiralana, S., Özaydinc, A., Özkand, G., Ramadane, M.F. 2019. Stability and volatile oxidation compounds of grape seed, flax seed and black cumin seed cold-pressed oils as affected by thermal oxidation. Grasas y Aceites, 70(1), e295.

Kiralan, M., Ramadan, M.F. 2016.Volatile oxidation compounds and stability of safflower, sesame, and canola cold-pressed oils as affected by thermal and Microwave treatments. Journal of Oleo Science, 65(10), 825-833.

Kostadinovic-Velickovska, S., Mitrev, S. 2013. Characterization of fatty acid profile, polyphenolic content and antioxidant activity of cold-pressed and refined edible oils from Macedonia. Journal of Food Chemistry and Nutrition, 1, 16-21.

Lerma-Garcia, M.J., Simo-Alfonso, E.F., Chiavaro, E., Bendini, A., Lercker, G., Cerretani, L. 2009. Study of chemical changes produced in virgin olive oils with different phenolic contents during an accelerated storage treatment. Journal of Agricultural and Food Chemistry, 57, 7834-7840.

Marmesat, S., Morales, A., Velasco, J., Ruiz-Méndez, M.V, Dobarganes, M.C. 2009. Relationship between changes in peroxide value and conjugated dienes during oxidation of sunflower oils with different degree of unsaturation. Grasas y Aceites, 60 (2), 155 160.

Marquez-Ruiz, G., Martin-Polvillo, M., Velasco, J., Dobarganes, C. 2008. Formation of oxidation compounds in sunflower and olive oils under oxidative stability index conditions. European Journal of Lipid Science and Technology, 110, 465-471.

Matthäus, B. 2013. Quality parameters for cold pressed edible argan oils. Natural Product Communications, 8(1), 37-41.

Najafi, V., Barzegar, M., Sahari, M.A. 2015. Physicochemical Properties and Oxidative Stability of Some Virgin and Processed Olive Oils. Journal of Agricultural Science and Technology, 17, 847-858. 
Parker, T.D., Adams, D.A., Zhou, K., Harris, M., Yu, L. 2003. Fatty acid composition and oxidative stability of cold-pressed edible seed oils. Journal of Food Science, 68(4), 1240-1243.

Poiana, M.A. 2012. Enhancing oxidative stability of sunflower oil during convective and microwave heating using grape seed extract. International Journal of Molecular Sciences, 13, 9240-9259.

Poiana, M.A., Alexa, E., Moigradean, D., Popa, M. 2009. The influence of the storage conditions on the oxidative stability and antioxidant properties of sunflower and pumpkin oil. In Proceedings of the 44th Croatian \& 4th International Symposium of Agriculture, Opatija, Croatia, 449-453.

Ponchurdchai, C., Singkhonrat, J. 2016. Monitoring the effect of different storage conditions of cold-pressed rice bran oil. International Journal of Chemical Engineering and Applications, 7(4), 254-258.

Popa, M., Glevitzky, I., Dumitrel, G.A., Glevitzky, M., Popa, D. 2017. Study on peroxide values for different oils and factors affecting the quality of sunflower oil. Scientific Papers, 6, 137-140.

Prescha, A., Grajzer, M., Dedyk, M., Grajeta, H. 2014. The antioxidant activity and oxidative stability of cold-pressed oils. Journal of the American Oil Chemists Society, 91, 1291-1301.

Rabadán, A., Álvarez-Ortí, M., Pardo, JE., Alvarruiz, A. 2018. Storage stability and composition changes of three cold-pressed nut oils under refrigeration and room temperature conditions. Food Chemistry, 259, 31-35.

Seleim, M.A.A., Rashwan, M.R.A., El-Sharkawy, A.A., Beshara, R.R.S. 2008. Effect of storage periods on the stability of sunflower oil treated with natural antioxidants. Assiut Journal of Agricultural Sciences, 39(1), 53-66.

Velickovska, S.K., Ludger Bruhl, L., Mitrev, S., Mirhosseini, H., Matthaus, B. 2015. Quality evaluation of cold-pressed edible oils from Macedonia. European Journal of Lipid Science and Technology, 117(12), 2023-2035.

Ying, Q., Wojciechowska, P., Siger, A., Kaczmarek, A., Rudzińska, M. 2018. Phytochemical Content, Oxidative Stability, and Nutritional Properties of Unconventional Cold-pressed Edible Oils. Journal of Food and Nutrition Research, 6, 476-485.

Zeb, A., Khan, S., Khan, I., Imran, M. 2008. Effect of temperature, UV, sun, and white lights on the stability of olive oil. Journal of the Chemical Society of Pakistan, 30(5), 790-794. 